\title{
Linear trends in cloud top height from passive observations in the oxygen A-band
}

\author{
L. Lelli ${ }^{1}$, A. A. Kokhanovsky ${ }^{*}, 1$, V. V. Rozanov $^{1}$, M. Vountas $^{1}$, and J. P. Burrows ${ }^{1}$ \\ ${ }^{1}$ Institute of Environmental Physics and Remote Sensing, University of Bremen, Otto-Hahn-Allee 1, 28334 Bremen, Germany \\ *now at: EUMETSAT, Eumetsat Allee 1, 64295 Darmstadt, Germany
}

Correspondence to: L. Lelli (luca@iup.physik.uni-bremen.de)

Received: 21 October 2013 - Published in Atmos. Chem. Phys. Discuss.: 2 December 2013

Revised: 16 April 2014 - Accepted: 30 April 2014 - Published: 6 June 2014

\begin{abstract}
Measurements by the hyperspectral spectrometers GOME, SCIAMACHY and GOME-2 are used to determine the rate of linear change (and trends) in cloud top height (CTH) in the period between June 1996 and May 2012. The retrievals are obtained from Top-OfAtmosphere (TOA) backscattered solar light in the oxygen A-band using the Semi-Analytical CloUd Retrieval Algorithm SACURA. The physical framework relies on the asymptotic equations of radiative transfer, valid for optically thick clouds. Using linear least-squares techniques, a global trend of $-1.78 \pm 2.14 \mathrm{~m} \mathrm{yr}^{-1}$ in deseasonalized CTH has been found, in the latitude belt within $\pm 60^{\circ}$, with diverging tendencies over land $\left(+0.27 \pm 3.2 \mathrm{~m} \mathrm{yr}^{-1}\right)$ and ocean $\left(-2.51 \pm 2.8 \mathrm{~m} \mathrm{yr}^{-1}\right)$. The El Niño-Southern Oscillation (ENSO), strongly coupled to $\mathrm{CTH}$, forces clouds to lower altitudes. The global ENSO-corrected trend in $\mathrm{CTH}$ amounts to $-0.49 \pm 2.22 \mathrm{~m} \mathrm{yr}^{-1}$. At a global scale, no explicit regional pattern of statistically significant trends (at $95 \%$ confidence level, estimated with bootstrap technique) have been found, which would be representative of typical natural synoptical features. One exception is North Africa, which exhibits the strongest upward trend in $\mathrm{CTH}$ sustained by an increasing trend in water vapour.
\end{abstract}

\section{Introduction}

Tropospheric clouds are main players in the Earth's climate system. Characterization of long-term global cloud properties (top and bottom height, optical thickness and albedo, effective radius of droplets) aims to support radiation budget assessments as well as trace gas retrievals, and analy- sis of cloud interactions with aerosol particles and gases in the atmosphere. The altitude of a cloud plays a cardinal role because clouds at different heights (i.e. temperatures) exert different feedbacks. High-altitude clouds absorb infrared radiation that comes from the lower atmosphere and radiate like black bodies. Since the temperature contrast between elevated clouds and lower atmosphere is high, the clouds have a positive contribution on the local net energy balance. At the same time, their albedo is small because they are, in most cases, comparably thin. Thus, they can warm the atmosphere more than they cool it, exerting a positive feedback.

Conversely, low-altitude clouds are strongly reflecting objects owing to their high optical density but they ineffectually shield infrared radiation emitted by atmospheric gases to the outer space. The reason is that the temperature of low clouds is closer to the temperature of the ground and the local net energy balance is close to zero. These clouds in turn can cool the climate system more than they warm it and thus exert a negative feedback.

Loeb et al. (2012) observed this mechanism in a study that focused on clouds in the tropical belt. However, this situation may change when considering the Pacific Northeast over a decadal time window. Evidence of a positive feedback by low-level clouds has already been demonstrated (Clement et al., 2009). It is therefore likely that no general description is possible on a global scale and regional studies should be conducted instead.

Moreover, a critical aspect of any trend analysis is that, due to the limitation of a relatively short derived cloud top height $(\mathrm{CTH})$ time series, no statistical significance may be found. Previous works do not provide clear indications. The analysis of the 7-year GOME record (June 1996-May 2003) 
by Loyola et al. (2010) shows a change of $-4.8 \mathrm{~m} \mathrm{yr}^{-1}$ for the latitudinal belt within $\pm 60^{\circ}$. Davies and Molloy (2012) reported a decreasing global trend of $-40 \mathrm{mdecade}^{-1}$, as seen by MISR on the Terra platform. Evan and Norris (2012) showed that the previous results were affected by instrumental artifacts. Corrected MISR time series exhibit the opposite tendency, that is an increase of $+54 \mathrm{~m} \mathrm{decade}^{-1}$, supported by a MODIS (on Terra) upward trend of $+60.9 \mathrm{~m} \mathrm{decade}^{-1}$. The considered record length amounts to 8 years, from March 2003 throughout February 2010.

This study attempts to extend the cloud records including measurements of the three sensors GOME, SCIAMACHY and GOME-2 (hereinafter termed GSG). Since the launch of GOME, back in 1995, more than 17 years of data are now available and they form the observational basis of the present analysis (June 1996-May 2012).

The paper has the following structure. Section 2 describes how the monthly sampled cloud record is calculated from measured radiances. Section 3 introduces the model used to derive the rate of linear change in CTH. Section 4 presents the main results. First, an analysis of El Niño-Southern Oscillation (ENSO) as reflected in cloud properties is presented and trends in CTH are assessed. In the last section, the findings are summarized, with conclusions and outlook for future work.

\section{Data and methods}

The spaceborne nadir-viewing spectrometers Global Ozone Monitoring Experiment (GOME, Burrows et al., 1999), Scanning Imaging Absorption spectrometer for Atmospheric CHartographY (SCIAMACHY, Bovensmann et al., 1999) and GOME-2 (Callies et al., 2000) measure solar backscattered light at a spectral resolution of $0.24-1.48 \mathrm{~nm}$ (see Table 1 for their characteristics). At the time of processing, GOME L1b data were in their version 4.00 and SCIAMACHY L1b version 7.03 with consolidation degree U. GOME-2 L1b data for time window 01/2007-12/2009 were in the reprocessed stage, while near-real-time data have been used for January 2010-May 2012. Cloud fraction is obtained from broadband Polarization Measuring Device (PMD) measurements with the Optical Cloud Recognition Algorithm (OCRA) (Loyola and Ruppert, 1998). For GOME, cloud fraction (CF) is delivered bundled with L1b data, while CF for GOME-2 is taken from the off-line L2 reprocessed data set made available by DLR in the framework of EUMETSAT's O3M Satellite Application Facility. Cloud fraction for SCIAMACHY has been calculated at the University of Bremen with in-house OCRA implementation.

In particular, the sensors cover the wavelength range 758$772 \mathrm{~nm}$ (at $\approx 0.4 \mathrm{~nm}$ resolution) where one of the absorption bands of molecular oxygen, the $\mathrm{O}_{2}$ A-band, is situated. The A-band is exploited by the Semi-Analytical CloUd Retrieval Algorithm (SACURA) (Rozanov and Kokhanovsky, 2004)
Table 1. Technical specifications of the instruments used in this work. The bottom part of the table describes the polarization measuring devices (PMDs).

\begin{tabular}{|c|c|c|c|}
\hline & GOME & SCIAMACHY & GOME-2 \\
\hline Data availability & $1996-2011^{\mathrm{a}, \mathrm{b}}$ & $2002-2012^{\mathrm{c}}$ & $2007-2022^{\mathrm{d}}$ \\
\hline Equator crossing [hour] (LT) & 10:30 a.m. & 10:00 a.m. & 9:30 a.m. \\
\hline Global coverage [days] & 3 & 6 & 1.5 \\
\hline Spectral coverage [nm] & $237-794$ & $240-2400$ & $237-794$ \\
\hline Spectral resolution [nm] & 0.38 & 0.44 & 0.48 \\
\hline Viewing geometry & nadir & $\begin{array}{l}\text { nadir, limb, } \\
\text { occultation }\end{array}$ & nadir \\
\hline Ground pixel size $\left[\mathrm{km}^{2}\right]$ & $320 \times 40$ & $60 \times 40$ & $80 \times 60$ \\
\hline Swath width $[\mathrm{km}]$ & $\approx 960$ & $\approx 1000$ & $\approx 1920$ \\
\hline Polarization & $3 p$ & $6 p$ & $12(s, p)$ \\
\hline Spectral resolution [nm] & $100-160$ & $55-120$ & $2.8-40$ \\
\hline Spatial resolution $\left[\mathrm{km}^{2}\right]$ & $40 \times 20$ & $30 \times 7.5$ & $40 \times 5$ \\
\hline
\end{tabular}

8 April 2012. ${ }^{\mathrm{d}}$ Foreseen extension of GOME-2 records aboard Metop-B/C.

to generate $\mathrm{CTH}$ records in the following way: given the local fractional cloud cover $(f)$, the sun-normalized Earthshine reflectances are weighted with the Independent Pixel Approximation (IPA) (Marshak et al., 1995). In this way, the measured scene reflectance $R_{\text {mes }}$ is scaled to the cloud reflectance $R_{\mathrm{cl}}$ generated by a full cloudy ( $f=1$ ) and a cloudfree $(f=0)$ pixel with

$R_{\mathrm{mes}}=f R_{\mathrm{cl}}+(1-f) R_{\mathrm{s}}$.

The clear-sky reflectance $R_{\mathrm{S}}$ is substituted by the Minimum Lambert-Equivalent Reflectivity (MLER) taken from the global database Tropospheric Emission Monitoring Internet Service (TEMIS) (Koelemeijer et al., 2003).

It has been demonstrated (Kokhanovsky et al., 2007; Lelli et al., 2012) that CTH is not substantially affected by the scaling of the cloud reflection function with different values of fractional cloud cover as long as $f$ is known from an independent source. This statement is true regardless of $f$ and of instrumental spatial resolution, because the algorithm makes use of spectral ratios. From a physical point of view, it is also clear that, on the coarse footprint scales of the sensors used in this work, the cloud reflectance is dominated by the contribution of photons scattered directly back to the platform and not by horizontal photon transport. This is not true for spatially better resolved instruments for which a cloud volume may have side lengths comparable with the footprint size.

The cloud optical thickness (COT) is retrieved in the continuum at $758 \mathrm{~nm}$ and used for the computation of the forward TOA cloud reflectance with asymptotic approximations of radiative transfer (Kokhanovsky and Rozanov, 2004). Then, the minimal difference between $R_{\mathrm{cl}}$ and the forward spectrum (modelled with the analytical equations of radiative transfer) is iteratively looked for along the whole $\mathrm{O}_{2}$ A-band, at the nominal spectral sampling of the instruments. The distinctive feature of SACURA is the modelling of clouds as scattering layers instead of Lambertian reflectors (Koelemeijer et al., 2001); therefore radiative transfer 


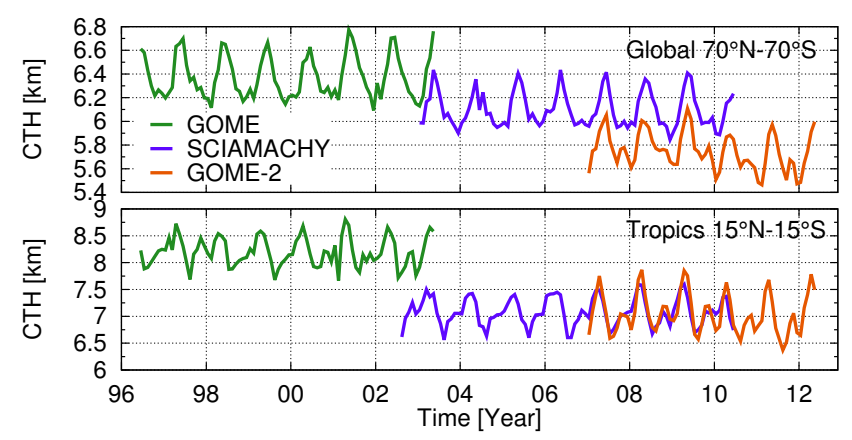

Figure 1. Time series of monthly means of CTH for global (top) and tropical (bottom) region.

throughout, above and below the clouds is taken into account. A comprehensive description of the algorithm can be found in Lelli et al. (2012, and references therein), where also accuracy, validation and selection criteria of $\mathrm{CTH}$ retrievals are given.

CTH retrievals $(b)$ are first binned in 13 height layers $(k)$ (see Table 2 for the grid definition), projected onto a equidistant rectangular grid of $0.5^{\circ}$-sided cells at latitude $(i)$ and longitude $(j)$, count-averaged over all altitudes $\left(c_{k}\right.$ being the retrieval counts at height bin $k$ ) at month $t$ and the $\mathrm{CTH}$ means $h_{t}$ are computed with

$h_{t}(i, j)=\frac{\sum_{k} c_{k t}(i, j) b_{k t}(i, j)}{\sum_{k} c_{k t}(i, j)}$.

This formulation has been chosen for consistency with Evan and Norris (2012, Eq. (1)). The values for $h_{t}$ are plotted in Fig. 1 for global (top) and tropical (bottom plot) regions. In both cases, the time series of the individual instruments exhibit in-phase seasonality for the respective overlapping months, whereas the relative offsets (top plot) cannot be explained by the mere diurnal cycle clouds have, owing to the different overpass time of the instruments which fly $1 / 2 \mathrm{~h}$ ahead of each other, GOME-2 crossing the equator first at 09:30 a.m. In the case of multi-layered cloud systems it is expected that sensors with coarser footprints, such as GOME $\left(320 \times 40 \mathrm{~km}^{2}\right)$, will observe more high clouds at the expense of low clouds as compared to finer-resolved sensors, such as SCIAMACHY $\left(60 \times 40 \mathrm{~km}^{2}\right)$ and GOME-2 $\left(80 \times 60 \mathrm{~km}^{2}\right)$. On an individual pixel scale, this effect can be seen in Lelli et al. (2012, Fig. 8, p. 1559), in which a GOME-derived CTH was co-located with a ground-based radar-derived CTH for a three-layer cloudy scene. GOME retrieved the height of the uppermost cloud layer. For larger time and spatial scales, this situation is depicted in Fig. 2, which shows retrieval counts $c_{k}$ (normalized to the total number of counts) as function of height bin $k$, for different instruments and for global (left) and tropical (mid plot) regions. The right plot of Fig. 2 shows the count difference between GOME and SCIAMACHY in both the global and tropical region. Especially in the tropics, where heterogeneity is frequent, GOME counts increase to-
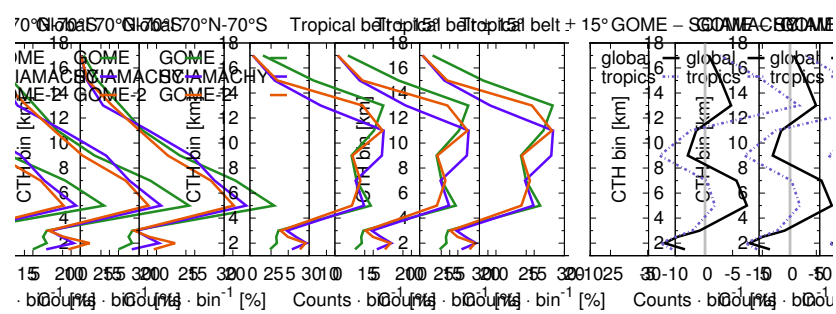

Figure 2. Relative pixel count as function of height for different instruments for global (left) and tropical (mid) region. (Right) Count difference between GOME and SCIAMACHY. The coarse GOME footprint favours the detection of high clouds over low clouds.

ward higher layers of the troposphere. These values can be devised as correction factors for the harmonization of time series among the instruments, given that the same scene is sensed and no time lag occurs between different measurements. Therefore, in the current analysis, it is preferred to compute the CTH anomalies of Fig. 3 subtracting the climatological seasonal cycle for each instrument separately, in order to avoid the introduction of post-hoc artifacts in the record.

Table 2. Description of the height grid for calculation and analysis of CTH time series.

\begin{tabular}{lrl}
\hline Cloud type & Height range $[\mathrm{km}]$ & Bins $[\mathrm{km}]$ \\
\hline Low & $0-3$ & $1-1.5,1.5-2$, \\
& & $2-2.5,2.5-3$ \\
Middle & $3-7$ & $3-5,5-7$ \\
High & $7-17$ & $7-9,9-11,11-13$, \\
& & $13-15,15-17$ \\
\hline
\end{tabular}

While the CTH anomalies from GOME and SCIAMACHY are in almost perfect agreement, the transition between SCIAMACHY and GOME-2 records is not smooth. The reason for discrepancies may be manifold. On one hand, a change in the PMD pixel definitions of GOME-2 was devised in April 2008 (EUMETSAT, 2010), which may have impacted cloud cover $f$ and the cloud reflection function $R_{\mathrm{cl}}$ of Eq. (1). On the other hand, radiometric calibration issues may also influence retrievals inferred from different instruments. For instance, van Diedenhoven et al. (2005) have shown that a difference of $20 \mathrm{hPa}$ in surface pressure retrieved in the oxygen A-band by GOME and SCIAMACHY could be corrected adding an offset of $0.86 \%$ to the TOA reflectance in the continuum at $756 \mathrm{~nm}$. However, tests have shown (see Appendix A) that radiometric uncertainties have almost no impact on the retrieved CTH with SACURA. This is a feature of the algorithm, which is based on spectral ratios and on the concurrent fit of $\mathrm{CTH}$ and $\mathrm{CBH}$ along the whole band.

For the ensuing analysis, the time series of GOME and SCIAMACHY are merged from June 2003 because the 
on-board tape recorder of GOME broke down and global coverage was not provided after May 2003. Time series of SCIAMACHY and GOME-2 were merged in May 2008. Given that SCIAMACHY is a thoroughly tested instrument and GOME-2 PMD definitions were updated in April 2008, we used SCIAMACHY anomalies prior to May 2008, even though GOME-2 data were available. For the rest of the time series, GOME-2 anomalies were used, as both instruments converge and exhibit good overlap. In fact, both instruments sense the strong negative CTH anomaly in year 2011. This feature dominates the whole time series and it gives us reasonable confidence that the order of magnitude as well as the sign of the CTH trend are not substantially affected, when using SCIAMACHY data.

\section{Trend model}

The basic requirement for the application of linear leastsquare regression is that the variable of interest is not persistent (Wilks, 2011). Persistence is the tendency for a variable to remain similar in time and is measured as the degree of temporal autocorrelation $r_{p}$. The data set of this study is sampled on a monthly basis, thus autocorrelation at lag $p=1 \mathrm{re}-$ veals the degree of persistence that $\mathrm{CTH}$ has after one month. The left plot of Fig. 4 shows the autocorrelation $r_{p}$ of $\mathrm{CTH}$ anomalies up to 4 months lag, for the global and tropical regions. It can be seen that in both cases the altitude of clouds exhibits barely any persistence. That is, the actual anomaly is not affected by values leading by one month. Since characteristic time scales of clouds range from minutes for individual shallow cloud cumulus to many hours for large stratiform cloud systems, over a month their features are randomized by intervening winds and persistence is not found. Therefore, methods for normally distributed (Gaussian) variables can be applied, given that the data set has been deseasonalized. In the right plot of Fig. 4 the mapped CTH autocorrelation signal (not exceeding $r_{p}=0.13$ over the Pacific Ocean) resembles ENSO-related patterns, stretching across the globe over the Atlantic and the Indian Oceans.

The trend magnitude $\beta$ is calculated, at latitude and longitude $(i, j)$, with

$$
\begin{aligned}
Y_{t}(i, j) & =\alpha(i, j)+\beta(i, j) \cdot X_{t}+\epsilon_{t}(i, j) \\
t & =1, \ldots, 192
\end{aligned}
$$

where $Y_{t}$ are the CTH anomalies, $X$ is the temporal variable sampled at monthly step $t$, and $\alpha$ and $\epsilon_{t}$ are the offset and the random noise, respectively. We emphasize that the time series of absolute values have been neither corrected for the impact of spatial resolution nor fitted directly. This is because the time series of Fig. 1 are shifted and the three instruments have different sensing local times. The chosen strategy has been to regress the time series of anomalies instead. This approach is analogous to the customary technique described in

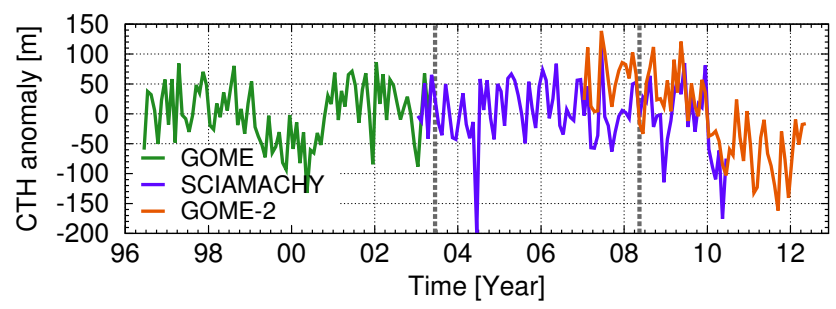

Figure 3. Monthly means of CTH anomaly. The dashed gray vertical lines show the months at which the time series have been merged (June 2003 and May 2008).

Mieruch et al. (2008, Eq. (1), p. 495, and references therein) and is reported below for convenience.

With $Y_{t}$ being the monthly mean of the variable of interest at time $t$ (for each geolocation point on the map), $\mu C_{t}$ the offsets of the regression line, $S_{t}$ the seasonal component, $\omega$ the desired change rate of the variable at time step $X_{t}$ and $N_{t}$ the noise, in the right hand side of

$Y_{t}=\mu C_{t}+S_{t}+\omega X_{t}+\delta U_{t}+N_{t}$

the term $\delta U_{t}$ describes the level shift $\delta$ allowed when concatenating time series from different instruments at time $T_{0}$, with a step function $U_{t}$ defined as

$U_{t}= \begin{cases}0, & t<T_{0} \\ 1, & t \geqslant T_{0}\end{cases}$

The removal of the sample mean for each respective month from the time series of absolute values allows the seasonality to be accounted for. The term $\delta U_{t}$ is incorporated by performing this step separately for each instrument. This is because the sample mean of anomalies is, by definition, centred about zero (Wilks, 2011) and the constant $\mu$ can be neglected ( $\mu$ being the mean value of $Y_{t}$ at time $t=0$ ). Eventually, Eq. (4) reduces to Eq. (3) and potential autocorrelative effects are embedded in the noise term.

Among the techniques for the estimation of confidence intervals of the trend magnitude $\beta$, bootstrap resampling (Efron and Tibshirani, 1993) enables the treatment of potentially non-normal data without any assumption on the underlying probability distribution. It belongs to the group of nonparametric methods and knowledge of the analytical form of the statistics is not required (Mudelsee, 2010). The guiding idea is the "plug-in" principle: a new scrambled data set is drawn (resampling with replacement) from the original data set and a new $\beta^{\prime}$ is calculated with Eq. (3). This procedure is repeated $n$ times and an empirical sample distribution for $\beta$ is estimated. This empirical distribution can be regarded as the approximated estimate to the unknown $\beta$ distribution and $\sigma_{\beta}$ can be associated with the random effects reflected in the data. The required confidence level is customarily chosen as $95 \%$, implying a $2.5 \%$ cut-off probability level on either side for a two-tailed distribution. When the probability 

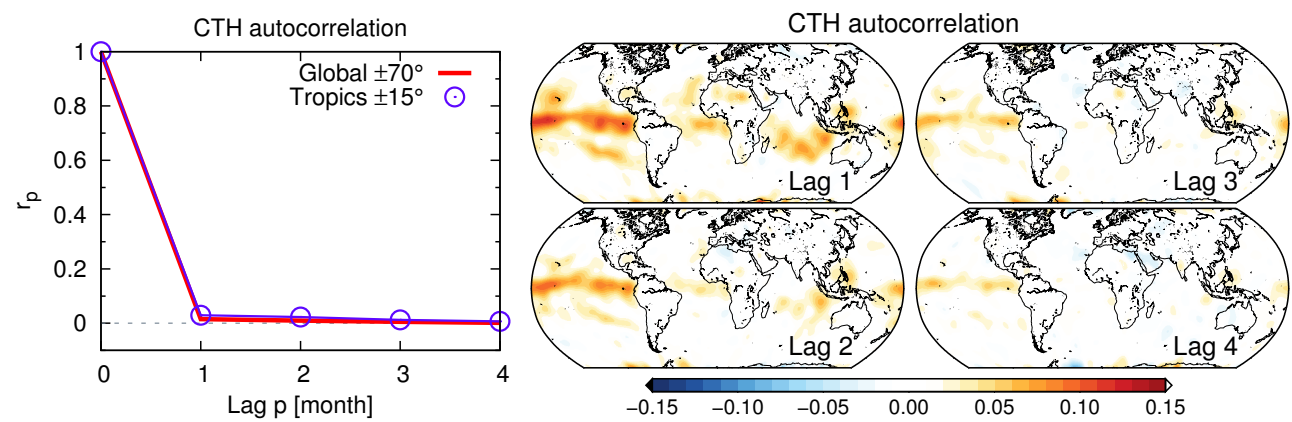

Figure 4. (Left plot) Autocorrelation function of CTH anomalies. Unlagged data $(p=0)$ correlate perfectly with themselves $\left(r_{0}=1\right)$. $r_{p}$ decays to almost 0 already at $p=1$. (Right plot) Maps of CTH autocorrelation for the first 4 months. ENSO-related patterns are seen over the Pacific, Indian and Atlantic Oceans.
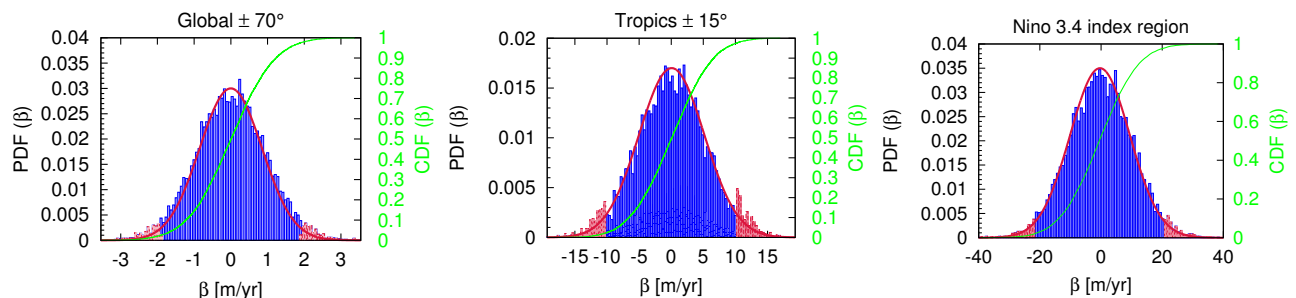

Figure 5. Normalized bootstrap (resamples $n=10^{4}$ ) distributions of trend $\beta$ for global (left), tropical (middle) regions and central East Pacific (right, $170-120^{\circ} \mathrm{W}, 5^{\circ} \mathrm{N}-5^{\circ} \mathrm{S}$ ). The red tails indicate the confidence interval (CI) at $95 \%$. A Gaussian distribution and a cumulative distribution function are plotted in red and green, respectively.

density function (PDF) of the unknown distribution is related to its standardized Gaussian approximation, the cutting-off level amounts to the mean value $\approx 1.96$ standard deviations $\sigma_{\beta}$ (Wilks, 2011, p.140). Therefore, at locations $(i, j)$ where the ratio $\left|\beta / \sigma_{\beta}\right|>2$, the trend magnitude $\beta$ exceeds natural variability and is considered statistically significant.

Figure 5 shows the normalized PDF and the cumulative density function (CDF) of $\beta$, calculated with $10^{4}$ bootstrap resamples, for global (left), tropical (middle) regions and the central East Pacific (right). The red tails of the PDF portray the confidence level calculated with the percentile method at $2.5 \%$ and $97.5 \%$ quantiles and provide the estimate of the uncertainty associated with the trend value $\beta$. We note that the condition of normality is reasonably satisfied even in the region of highest autocorrelation (i.e. central East Pacific, $170-120^{\circ} \mathrm{W}, 5^{\circ} \mathrm{N}-5^{\circ} \mathrm{S}$ ), as can be seen in the right plot of Fig. 5. Moreover, Fig. 6 displays the theoretical residual quantiles, estimated after regression with the linear model and application of the parameter estimates $\hat{\alpha}$ and $\hat{\beta}$ of Eq. (3) against the sample distribution of global CTH anomalies. Since the majority of points cluster about the straight line, the linear model seems to be a reasonable assumption, given that the autocorrelation function of Fig. 4 drops almost to zero after one month.

Therefore, the major process that still can influence the time series is the quasi-stationary ENSO. Laken et al. (2012) indirectly came to a similar conclusion, while analysing the effect of solar activity on cloud altitudes with MODIS Terra and Aqua measurements. Norris (2005) comes to the same conclusion as well. The ENSO periodicity is still a matter of on-going research (Solomon and Newman, 2012) and is not the focus of this work.

\section{Results}

\subsection{Cloud property changes coupling to ENSO}

The ENSO has been recognized as the largest natural fluctuation that can establish teleconnections and modulate cloud properties. ENSO has to be understood as the tie between two different processes (Trenberth, 1997): the term El Niño is assigned to a yearly warming of the ocean current which streams along the coasts of Peru and Ecuador in late December. Regularly, but not every year, a more pronounced warming of the wide tropical East Pacific pool occurs, driven by the magnitude of trade wind flows. The atmospheric component of this perturbation is termed the Southern Oscillation. The opposite phase, namely La Niña, corresponds to a cooling of the Pacific Basin. Quantitatively, ENSO is identified when sea surface temperature (SST) gradient changes over the central East Pacific $\left(170-120^{\circ} \mathrm{W}, 5^{\circ} \mathrm{N}-5^{\circ} \mathrm{S}\right)$ exceed $\pm 0.5^{\circ} \mathrm{C}$, resulting in the standard Niño 3.4 climate index (U.S. National Centers for Environmental Prediction (NCEP), 1993). 


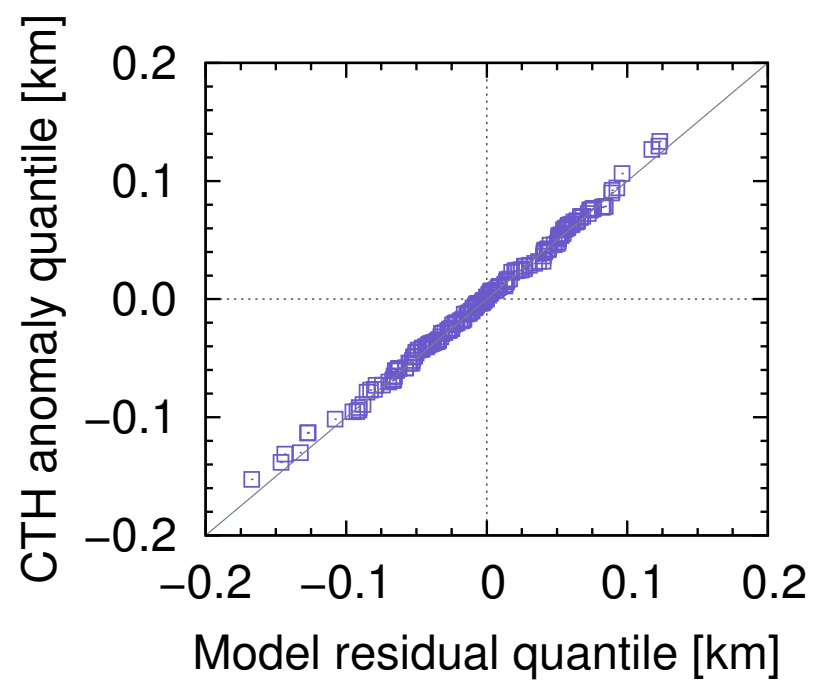

Figure 6. Normal quantile-quantile plot for global CTH anomalies vs. the theoretical residual quantiles estimated after regression with Eq. (3) and application of the parameter estimates $\hat{\alpha}$ and $\hat{\beta}$.

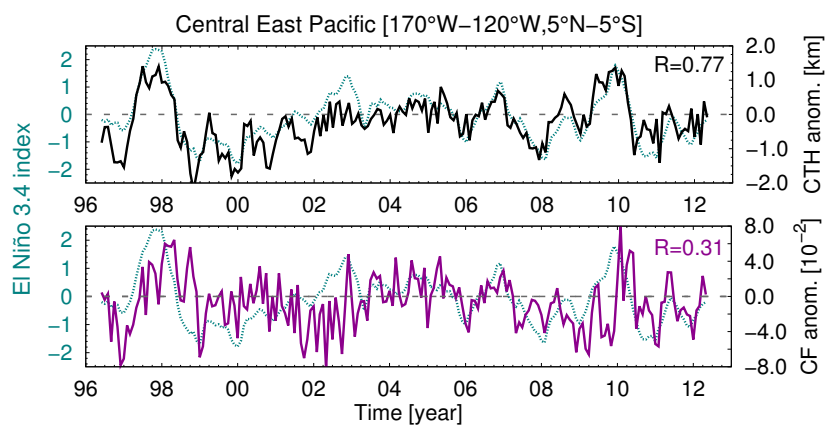

Figure 7. Time series of CTH (top) and CF (bottom) anomaly over the central East Pacific with the El Niño 3.4 index.

In Fig. 7 the Niño 3.4 index has been plotted together with the unsmoothed $\mathrm{CTH}$ and $\mathrm{CF}$ anomalies for the 17 years of the GSG data set, and high $(R=+0.77)$ and moderate $(R=+0.31)$ correlations are observed for $\mathrm{CTH}$ and $\mathrm{CF}$, respectively. It can also be noted that the maxima of the CF time series are not in phase with the warm ENSO phases and are delayed by approximately 2 months. The CTH and CF anomaly time series have been partitioned for high clouds (defined as clouds with altitude $h>7 \mathrm{~km}$ ), middle clouds $(3 \mathrm{~km}<h<7 \mathrm{~km})$ and low clouds $(h<3 \mathrm{~km})$, smoothed with a 6-month running mean and plotted in Fig. 8. The correlation coefficients (calculated with unsmoothed data) reported on the right clearly indicate that a warm (cold) ENSO phase corresponds to a decrease (increase) in CF for low $(R=-0.55)$ and middle $(R=-0.31)$ clouds, while high clouds increase (decrease) their coverage $(R=+0.53)$. In Fig. 8 it is also shown that the lagged extrema in the columnaveraged CF of Fig. 7 originate in the lowest layers of the troposphere, because CF for low- and mid-level clouds al- ways anticipates the extrema for high clouds by a constant lag of 2 months.

More precisely, the coupling of CTH and CF to ENSO can be understood by inspecting Fig. 9, where $R$ for either cloud parameters has been plotted as a function of altitude bin $h$. Starting from the planetary boundary layer (PBL) $(h<2 \mathrm{~km})$, a warmer ocean surface produces evaporation and CF increases $(R=+0.39)$, while CTH exhibits barely any correlation $(R=-0.11)$. Departing from the PBL ( $2 \mathrm{~km} \leq h<8 \mathrm{~km}$ ), the cloud field is compressed by winds (CF decreases in response to warming, $-0.30 \leq R \leq-0.41$ ) and convection lifts clouds higher up (CTH increases in response to warming, $+0.16 \leq R \leq+0.38$ ). Within the upper layer of the troposphere $(h \geq 8 \mathrm{~km})$, clouds rise until the tropopause $(h \approx 16-17 \mathrm{~km})$ stops their ascent $(-0.11 \leq$ $R \leq 0$ ) and, concurrently, extend (CF increases, $+0.19 \leq$ $R \leq+0.44$ ), following the divergent air flow toward zones of lower pressure. This is consistent with the picture of a reinforced meridional circulation which squeezes clouds at low altitudes, while high clouds spread out in the horizontal direction and air masses close the Hadley cell. In fact, positive correlations between $\mathrm{CF}$, SST and surface convergence are found by Norris (2005) for the International Satellite Cloud Climatology Project (ISCCP) high cloud amount and the ground-based Extended Edited Cloud Report Archive (EECRA) high-cloud record, calculated over almost the same region. Conversely, the warm pool situated in the western tropical Pacific $\left(30^{\circ} \mathrm{N}-30^{\circ} \mathrm{S}\right.$ and $\left.100-160^{\circ} \mathrm{E}\right)$ is characterized by the reverse situation: deep convective clouds occur during cold La Niña periods. Hence negative correlations between CF and SST are found (Norris, 2005; Marchand, 2013). This dipole-like ENSO influence on cloud properties can be seen in Fig. 10, where diagrams of COT-CTH are drawn for the strongest ENSO within the GSG record (i.e. El Niño April 1997-May 1998 and the ensuing La Niña June 1998-June 2001) over the Niño 3.4 index box and the tropical warm pool.

Bjerknes (1969) has already pointed out how trade winds and SST mutually strengthen for both ENSO phases. Interestingly, he also argued that the ocean response to a change of the wind circulation patterns during El Niño has a characteristic lag of 2 months (this mechanism is known as the Bjerknes feedback), similar to the lag seen in the CF anomaly time series of Figs. 7 and 8. It is tempting to regard this similarity as the manifestation of a two-way coupling between cloud properties and SST. However, the dynamical interpretation rather than the energetic interpretation is preferred here for two reasons: not only have the curves and the correlations of Fig. 8 been calculated for the narrow Niño 3.4 climate index box, located in the central East Pacific, where the effect of the weakening of the longitudinal Walker circulation (corresponding to the onset of teleconnections) is at its maximum, but also Dessler (2011) showed that cloud changes have a negligible impact on SST, due to heat storage capacity and 
Table 3. Overview of trends in cloud height $\left[\mathrm{m} \mathrm{decade}^{-1}\right]^{\mathrm{a}}$. Trends derived from the GSG data set are given with (left column) and without (right column) ENSO, that has been filtered masking any data within the Niño 3.4 climate index box $170-120^{\circ} \mathrm{W}, 5^{\circ} \mathrm{N}-5^{\circ} \mathrm{S}$

\begin{tabular}{lrrrrrr}
\hline Base period [year/month] & MISR & MISR corr. & MODIS & GOME & \multicolumn{2}{c}{ GSG } \\
\hline $03 / 03-11 / 02$ & $-40.1^{\mathrm{b}}$ & $+54.3^{\mathrm{c}}$ & $+60.9^{\mathrm{c}}$ & - & -10.7 & +8.4 \\
$96 / 06-03 / 05$ & - & - & - & $-47.9^{\mathrm{e}, \mathrm{d}}$ & $-67.2^{\mathrm{e}}$ & $+25.2^{\mathrm{e}}$ \\
$96 / 06-12 / 05$ & - & - & - & - & -17.8 & -4.9 \\
\hline
\end{tabular}

${ }^{\mathrm{a}}$ The GSG trends are recalculated for the length of the referenced data set and latitude belt $\pm 60^{\circ}$. ${ }^{\mathrm{b}}$ Davies and Molloy (2012). ${ }^{\mathrm{c}}$ Evan and Norris (2012). ${ }^{\mathrm{d}}$ Loyola et al. (2010). ${ }^{\mathrm{e}}$ Extrapolated to decade.

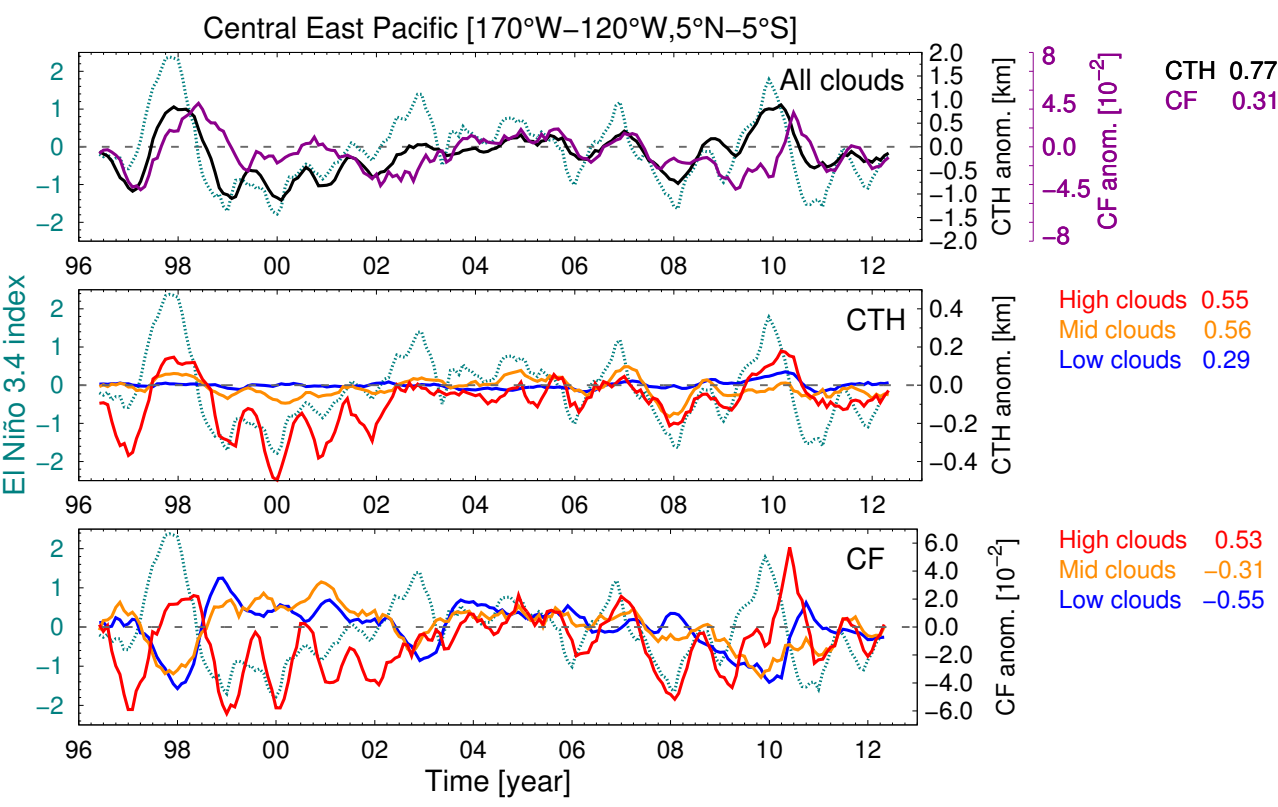

Figure 8. (Top plot) Time series of CTH (black curve) and cloud fraction (purple) anomaly over the central East Pacific with the El Niño 3.4 index and Pearson's correlation coefficient. (Middle plot) CTH and (bottom plot) CF anomalies subset for low- (blue), mid- (orange), and high-level (red) clouds. Time series smoothed with a 6-month running mean. Correlation coefficients calculated with unsmoothed data.

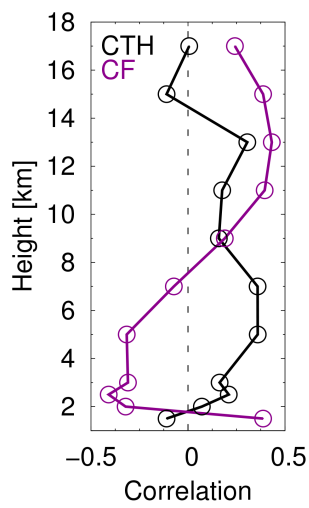

Figure 9. Correlation coefficient of CTH and CF with the El Niño 3.4 index as function of height for the 17 years of the GSG data set. Region considered: central East Pacific (170-120 $\left.\mathrm{W}, 5^{\circ} \mathrm{N}-5^{\circ} \mathrm{S}\right)$. heat transport of the ocean, which dominates the ENSO climate variability.

The relationship between CTH, CF and ENSO has been investigated by Erlykin and Wolfendale (2010). Through the analysis of the ISCCP cloud cover and top pressure, they assert that both ENSO phases and global Earth's low troposphere temperature are negatively correlated with low-cloud amount. Thus, in the periods influenced by warm El Niño, low clouds are lifted higher up and are reclassified as midlevel clouds. The opposite holds true for periods driven by La Niña. Since the last decade is showing more frequent cold episodes (59\% vs. $41 \%$ occurrence of warm phases, see also Loeb et al., 2012), it is reasonable to suppose that the ENSO pulls clouds down.

\subsection{Trends in CTH}

Figure 11 supports the argument introduced in the previous section: the removal of ENSO (excluding any data within 
Central-East Pacific $\left[5^{\circ} \mathrm{N}-5^{\circ} \mathrm{S}, 170^{\circ} \mathrm{W}-120^{\circ} \mathrm{W}\right]$

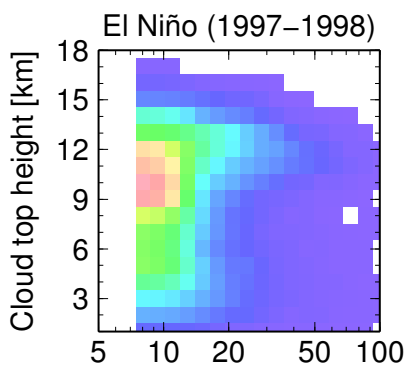

Cloud optical thickness

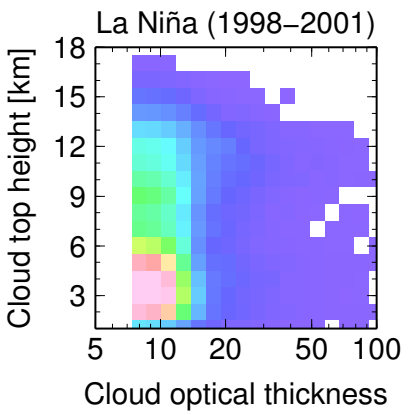

Western Pacific $\left[30^{\circ} \mathrm{N}-30^{\circ} \mathrm{S}, 100^{\circ} \mathrm{E}-160^{\circ} \mathrm{E}\right]$

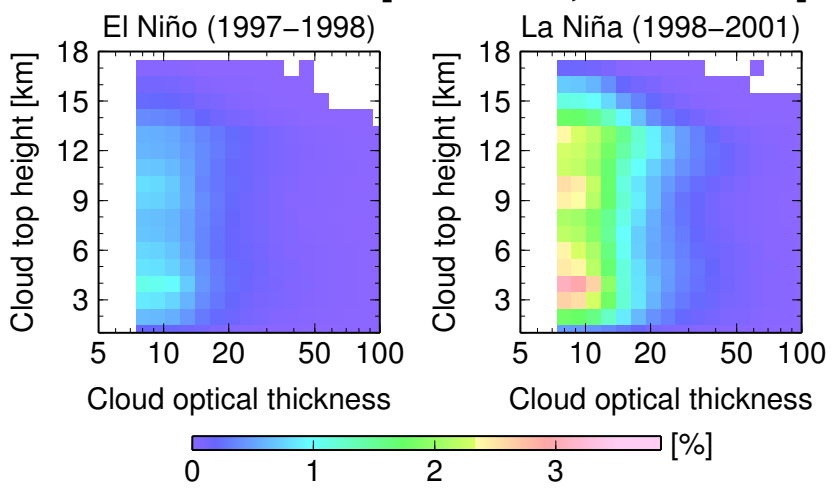

Figure 10. ISCCP-like diagrams of COT vs. CTH for a warm (left column) and cold (right column) ENSO phase between April 1997 and June 2011 over the Niño 3.4 index box (top row) and the western tropical warm pool (bottom row).

longitudes of 170 and $120^{\circ} \mathrm{W}$ and latitudes of $5^{\circ} \mathrm{N}$ and $5^{\circ} \mathrm{S}$ ) shifts the overall trend, calculated in the latitudinal belt $\pm 60^{\circ}$ (in order to lessen the influence of ice-capped regions), from -30.26 to $-8.33 \mathrm{~m}$ over 17 years.

The time series has been analysed with respect to underlying surface and a trend of $-2.51 \mathrm{~m} \mathrm{yr}^{-1}$ over ocean and $+0.27 \mathrm{~m} \mathrm{yr}^{-1}$ over land are identified (lower plot of Fig. 11). No exhaustive explanation can be found for this divergent land/water trend on a global scale, due to the complexity and variety of tropospheric processes influencing the clouds. On a global scale, such effects might average out and give rise to well-defined cloud changes. Even so, it has been noted (Wagner et al., 2008) that CTH reacts in response to a change in near-surface temperature (ST). The authors analysed 7.5 years of GOME data and showed not only a strong positive correlation between CTH and ST, but also that ST changes are highest over land. Thus, at the simplest level, global patterns of ST might explain the information concealed in the diverging land/ocean CTH trends.

The findings are summarized in Table 3 together with previous results from independent data sets. The reported values show discrepancies. Indeed, the length of data sets as well as the instrumental spatial resolution can alter the rate of linear change in $\mathrm{CTH}$, because different cloud features are

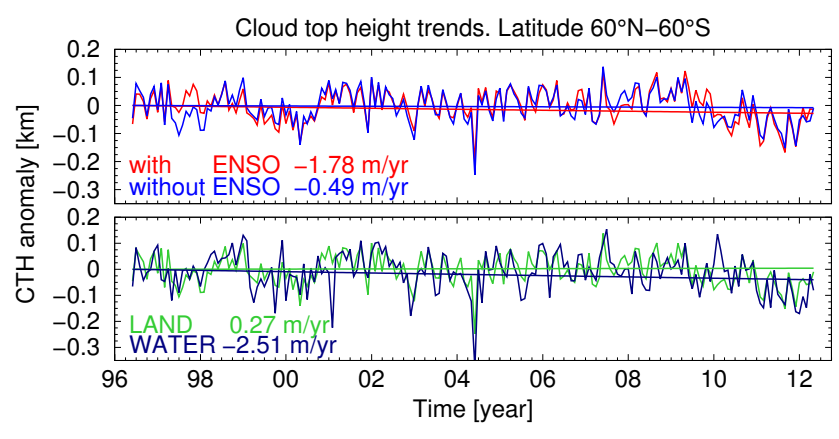

Figure 11. (Upper plot) Global trend $\beta$ in CTH anomalies in the latitude belt $\pm 60^{\circ}$, with (red line) and without (blue line) ENSO region. (Lower plot) The time series are broken up for underlying surface. Abundances of land and water masses between $60^{\circ} \mathrm{N}$ and $60^{\circ} \mathrm{S}$ are 0.264 and 0.736 , respectively.

sensed, both in space and time. It should be also noted that retrieved cloud properties and, therefore, trends are affected by the choice of the spectral window used in the algorithms. IR-based algorithms are sensitive to cirrus clouds, whereas NIR-based algorithms, such as SACURA, are valid for thick clouds. Moreover, SACURA takes into account $\mathrm{O}_{2}$ absorption inside the clouds and the retrieved cloud height cannot be regarded as effective, since it will be closer to its geometrical top in the case of a single-layer cloud.

Fig. 12 shows global maps of trend magnitude $\beta$ and standard deviation $\sigma_{\beta}$, degraded to $5^{\circ}$-sided cell mesh for computational efficiency and smoothed with the eight neighbouring cells. The maps indicate that trend magnitudes are zonally partitioned. The strongest trends are found over North Africa and the Arabian subcontinent $\left(>+45 \mathrm{~m} \mathrm{yr}^{-1}\right)$, central East Pacific $\left(-30 \mathrm{~m} \mathrm{yr}^{-1}\right)$ and the Indian Ocean $\left(-15 \mathrm{~m} \mathrm{yr}^{-1}\right)$. Conversely, the mid-latitudes $\left(60-30^{\circ} \mathrm{N}\right.$ and $\left.30-60^{\circ} \mathrm{S}\right)$ are homogeneously characterized by a slightly decreasing trend $\left(-2 \mathrm{~m} \mathrm{yr}^{-1}\right.$ on average). Figure 12 shows also that the trend variability follows the oceanic contours, being almost always greater than $20 \mathrm{~m} \mathrm{yr}^{-1}$ over water in the latitude belt $\pm 30^{\circ}$ and smaller than $15 \mathrm{~m} \mathrm{yr}^{-1}$ otherwise. Table 4 summarizes zonal values of $\mathrm{CTH}$ trend for the tropics and the mid-latitudes, over land and water masses.

Analogous conclusions are indirectly drawn by Marchand (2013), who analysed MISR (on board the TERRA platform) cloud amount as a function of cloud (top) height. Specifically, linear trends of cloud amount over oceanic regions are shown in Marchand (2013, Fig. 6, p. 1946). It can be seen that where high cloud amount decreases low clouds are more frequent. This effect can be seen over the northeast Pacific and over the central East Pacific. Hence the author suggests a net decrease in mean CTH. Notwithstanding the different length of the time series (MISR covering the period 2001 to 2011), we observe a similar tendency in $\mathrm{CTH}$ over the same regions, which is evident in the left plot of Fig. 12. The opposite also holds true: regions showing 

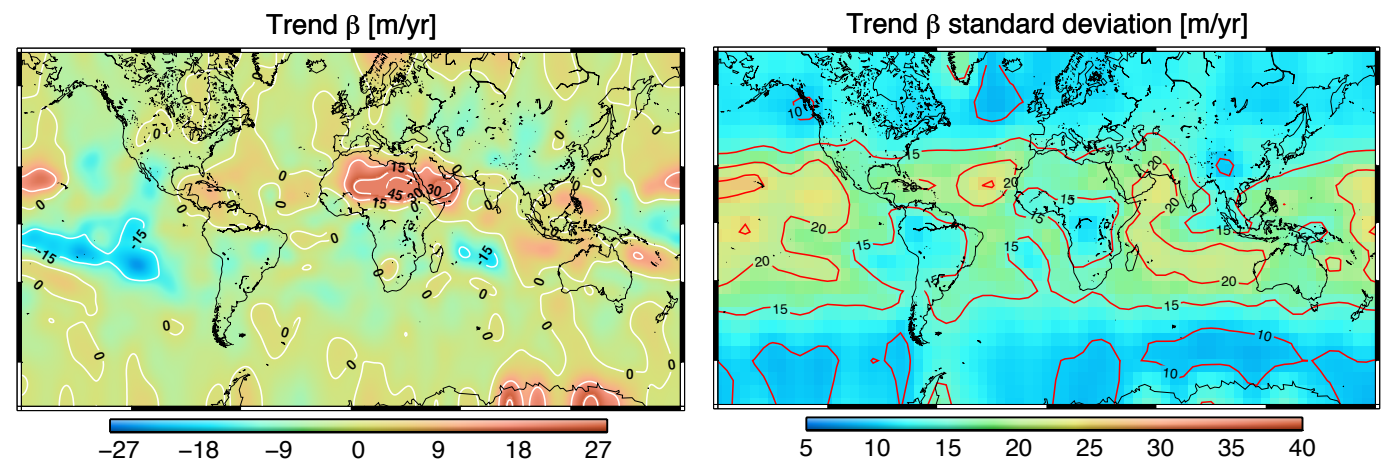

Figure 12. Global map of linear trend $\beta$ in $\mathrm{CTH}$ (left) and standard deviation $\sigma_{\beta}$ (right).

Table 4. Overview of zonal trends in CTH $\left[\mathrm{m} \mathrm{yr}^{-1}\right.$ ], ENSO excluded, masking any data within the box $170-120^{\circ} \mathrm{W}, 5^{\circ} \mathrm{N}-5^{\circ} \mathrm{S}$. Bootstrap resamples $n=10^{3}$. The zonal values are not weighted by the respective land and water abundances.

\begin{tabular}{llllcc}
\hline & Belt & & Land + water & Land & Water \\
\hline \multirow{2}{*}{ With ENSO } & Tropics & $5^{\circ} \mathrm{N}-5^{\circ} \mathrm{S}$ & $-4.34 \pm 5.65$ & $-1.56 \pm 4.02$ & $-5.15 \pm 8.21$ \\
& Tropics & $20^{\circ} \mathrm{N}-20^{\circ} \mathrm{S}$ & $-2.16 \pm 2.97$ & $+1.83 \pm 4.40$ & $-3.39 \pm 5.32$ \\
& Mid-latitude & $30-60^{\circ} \mathrm{N}$ & $-2.17 \pm 1.52$ & $-2.85 \pm 4.23$ & $-1.52 \pm 3.68$ \\
& Mid-latitude & $30-60^{\circ} \mathrm{S}$ & $-2.71 \pm 2.59$ & $-2.70 \pm 9.25$ & $-2.71 \pm 2.47$ \\
Without ENSO & Tropics & $5^{\circ} \mathrm{N}-5^{\circ} \mathrm{S}$ & $-1.80 \pm 6.00$ & $-1.43 \pm 5.05$ & $-1.99 \pm 8.52$ \\
& Tropics & $20^{\circ} \mathrm{N}-20^{\circ} \mathrm{S}$ & $+0.53 \pm 3.53$ & $+5.93 \pm 5.33$ & $-1.74 \pm 4.36$ \\
& Mid-latitude & $30-60^{\circ} \mathrm{N}$ & $-2.11 \pm 3.09$ & $-2.72 \pm 4.60$ & $-1.53 \pm 3.70$ \\
& Mid-latitude & $30-60^{\circ} \mathrm{S}$ & $-2.78 \pm 2.54$ & $-3.24 \pm 8.77$ & $-2.75 \pm 2.35$ \\
\hline
\end{tabular}

increasing occurrence of high clouds exhibit a decrease in low cloud amount. Consequently, the mean CTH is expected to increase, as seen over Indonesia and, to a lesser extent, over the central Atlantic.

Statistically significant (at $95 \%$ confidence level) trends are plotted in Fig. 13. No patterns are discernible that can be easily classifiable in the context of natural synoptic cloud variability, except for the decrease over central East Pacific and the increase over North Africa. The main difference between Figs. 12 and 13 is that the CTH increase over the Arabian peninsula is not significant. To investigate this effect, the two regions are magnified on a continental scale, labelled R1 (North Africa) and R2 (Arabian Peninsula), and their trends in CTH are plotted in Fig. 14 (top row). Both regions are naturally arid areas, which do not exhibit any notable evaporation. Any cloud field over R1 and R2 is likely the result of moist air transport from neighbouring water basins. For this reason, a water vapour $\left(\mathrm{H}_{2} \mathrm{O}\right)$ data set has been added and analysed in Fig. 14. The data set has been derived from the same instruments used for generation of the cloud data records and is described by Noël et al. $(2004,2005)$ and Mieruch et al. (2008).

It can be seen that the significant $\mathrm{CTH}$ trend over $\mathrm{R} 1$ is sustained by an increasing trend in $\mathrm{H}_{2} \mathrm{O}$. Conversely, the decreasing trend in $\mathrm{H}_{2} \mathrm{O}$ over $\mathrm{R} 2$, which has been reported to be statistically significant (Mieruch et al., 2008), is anticor-

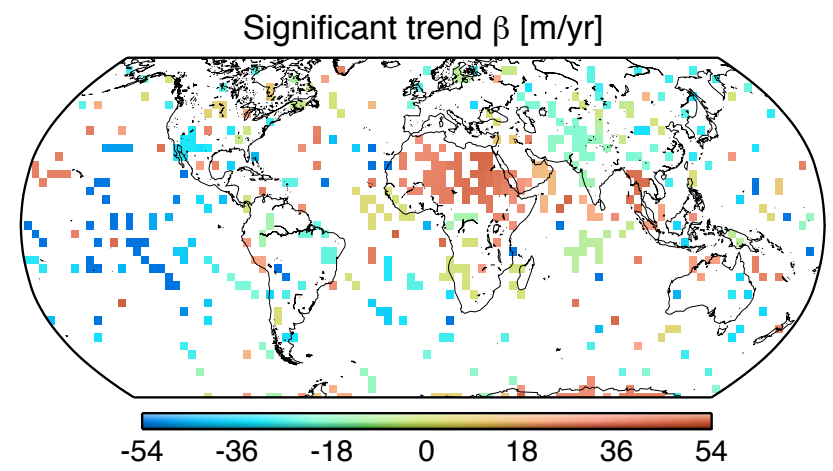

Figure 13. Global trend $\beta$ in $\mathrm{CTH}$ anomaly, statistically significant at $95 \%$ confidence level. Data are gridded onto a mesh of $2^{\circ}$-sided cells.

related with $\mathrm{CTH}$. An explanation may be found in largescale outflows of fine-mode soot particles, that are produced in the Indian subcontinent during biomass burning seasons and transported over R2 (but not over R1) by easterly winds during the winter phase of the Indian monsoon. Indeed, most of the decreasing trend in $\mathrm{H}_{2} \mathrm{O}$ is seen during winter seasons (Fig. 14, middle right), while almost no trend is seen in summer months (Fig. 14, middle left). The absorption of solar radiation by soot gives rise to two competing effects. On one 

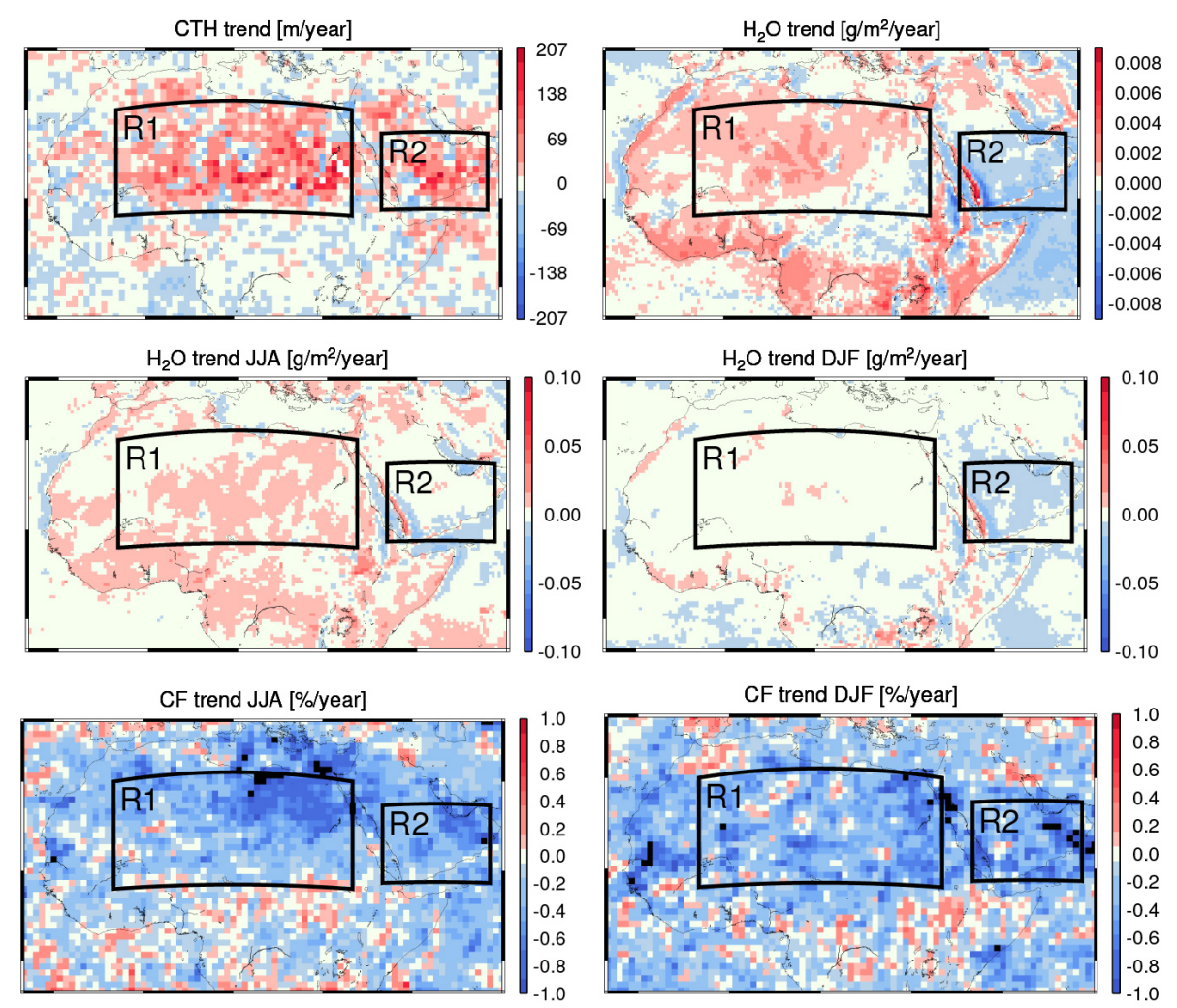

Figure 14. Maps of linear trends over North Africa (R1) and the Arabian Peninsula (R2) for (top left) CTH anomalies and (top right) columnar water vapour anomalies $\left[\mathrm{g} \mathrm{m}^{-2} \mathrm{yr}^{-1}\right.$ ]. The latter is subset for (middle left) summer (JJA) and (middle right) winter (DJF) months. Linear trends for $\mathrm{CF}$ anomalies are plotted in the bottom row, for summer (left) and winter (right) months.

hand, soot warms the atmospheric column (Feingold, 2005) and may cause clouds to dry out (Ackerman et al., 2000). On the other hand, soot depletes the amount of radiation reaching the surface, exerting a negative radiative forcing (Nakajima and Schulz, 2009), and the amount of energy at disposal for evaporation is diminished. Further arguments supporting a decrease in surface insulation of the Indian Ocean have been reviewed, among others, by Turner and Annamalai (2012).

In general, changes in column-averaged CTH might be explained by changes in cloud cover in different altitude layers. When looking at the trend in annual CF anomalies (not shown here) a constant decreasing tendency is suggested. This is consistent with long-term changes derived by other instruments (Stubenrauch et al., 2013) for the same region. In the bottom row of Fig. 14 the breakups in summer (JJA) and winter (DJF) months are portrayed. Cloud fraction trends do not exhibit seasonality and are not correlated with the seasonal Indian monsoon because the trends over R1 and R2 are commensurate and have equal sign, which would not be the case otherwise. This finding agrees with Norris (2001).

The question of whether a change in cloud parameters (fraction, optical thickness and top height) translates into a change in columnar water vapour (due to the assumption in the algorithm of ghost column under the cloud) has been re- cently addressed by du Piesanie et al. (2013). They analysed SCIAMACHY water vapour columns and cloud products, generated with the same algorithms of the data sets used in this work (AMC-DOAS, Noël et al. (2004, 2005); SACURA, Rozanov and Kokhanovsky, 2004). The authors showed that water vapour columns are influenced neither by changes in $\mathrm{CF}$ nor in cloud optical thickness. The dependence of $\mathrm{H}_{2} \mathrm{O}$ total column on changes in cloud top height has been explored for cases with $\mathrm{CF} \geqslant 0.9$. Even for these very cloudy scenes, a change in $\mathrm{CTH}$ of $\approx 450 \mathrm{~m}$ over 17 years cannot explain the decrease of $\approx-0.85 \mathrm{~g} \mathrm{~cm}^{-2}$ above the Arabian Peninsula for the same time span. This argument rules out algorithmic artifacts due to the shielding of water vapour by clouds and points to a real process, which presumably takes place over the northern Indian Ocean.

\section{Conclusions}

For the first time, spaceborne passive measurements of the $\mathrm{O}_{2}$ A-band have been used to identify the rate of linear change (trend) in CTH anomalies for the period June 1996-May 2012. The instruments used in this work are hyperspectrally resolved spectrometers (i.e. GOME, SCIAMACHY and GOME-2), payloads of polar orbiting 


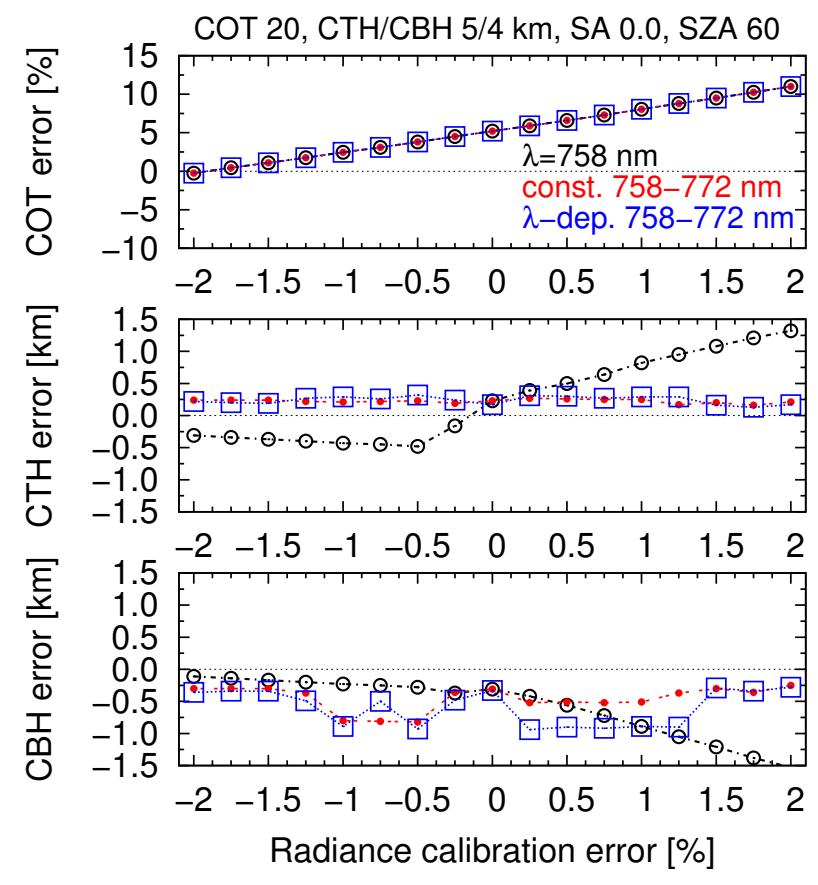

Figure 15. Errors in retrieved cloud optical thickness (\%, top plot), cloud top and bottom height $(\mathrm{km}$, middle and bottom plot) for a single-layered cloud, placed at 5-4 km altitude and optically dense 20 , above a dark surface. Three different offsets in radiance are applied: single-channel at $\lambda=758 \mathrm{~nm}$ (black curves); constant, added along the whole band (red curves); linearly spectral-dependent, as described in Noël (2005) (blue curves).

platforms which cross the Equator at mid-morning (local time). In particular, it has been seen that the instrumental spatial resolution impacts the calculation of mean values of apparent $\mathrm{CTH}$ at a monthly sampling. Owing to the sensing time lag among the instruments, the anomaly time series have been calculated for each sensor separately, once the climatological mean state of the cloud property of interest has been subtracted. Given that cloud top height, at monthly sampling, does not exhibit any significant persistence in time, the rate of linear change has been calculated with linear regression methods. The estimation of the distribution of CTH trends with bootstrap technique enabled the computation of confidence intervals and, consequently, the assessment of statistical significance.

First, CTH and, to a minor extent, cloud cover have been found to be coupled to ENSO in a dipole-like fashion across the Pacific Ocean. Patterns of CTH autocorrelation of magnitude $0.12-0.13$ (vanishing after approximately 6 months) are seen over the central East Pacific, Atlantic and Indian Oceans, resembling the large-scale fluctuations induced by ENSO. Moreover, the hallmark of the cold tongue in the central eastern Pacific is correlated with the strongest decreasing trend in cloud top height. The anomaly time series of Fig. 3 clearly exhibits two dips, centred at the beginning of years 2000 and 2011. They resemble La Niña's periodicity, pointing to the ENSO's role in the overall decreasing trend in $\mathrm{CTH}$.

Second, except for trends derived from the same instrument (i.e. GOME), the comparison with trends previously published in the literature displays differences which cannot be easily understood within a single explanation. In the case of MODIS and MISR trends (Evan and Norris, 2012), one notes that those instruments not only differ in spatial sampling but are also sensitive to thin clouds, in both solid and liquid phase. These clouds cannot be detected with the hyperspectral sensors in the $\mathrm{O}_{2}$ A-band used in this work. Thus, the biases shown in Table 3 might point to a recent increasing trend of thin, typically cirrus, clouds. This argument could be also substantiated by the moderate decreasing CTH trend seen in both hemispherical mid-latitudes: since there is evidence on the widening of the Hadley cell (Allen et al., 2012, and references therein), the poleward displacement of cloudiness (Eastman and Warren, 2013) and the concurrent upward shift of high clouds on a synoptic scale (inferred from modelling studies, Singh and O'Gorman 2012), this picture implies a systematic thermodynamic phase change in high clouds. As a consequence, a lower occurrence of warm (liquid) clouds in the upper atmospheric layers suggests a higher occurrence of cirrus clouds (undetectable with the $\mathrm{O}_{2}$ A-band), with the net effect of lowering the mean columnar $\mathrm{CTH}$, as seen in the current data set.

Preliminary analysis of the trends seen over North Africa and the Arabian Peninsula suggests a semi-direct aerosol effect on clouds. Natural and anthropogenic soot particles have an impact on $\mathrm{CTH}$, modulating insulation and water evaporation over the Indian Ocean. Subsequently, during the winter phase of the Indian Monsoon, transport of moist air masses over the arid Arabian Peninsula exerts a negative feedback and decreases the statistical significance of clouds' vertical displacement. In fact, this effect has been already seen over Europe during the economic, industrial and infrastructural adjustments following the fall of the Eastern Bloc (Devasthale et al., 2005). However, this topic deserves in-depth investigation, which we defer to a later publication.

In general, the representativeness of every trend is affected by the record length under study; 17 years of data still might not be enough to provide any decisive answer to current open questions involving clouds. Future planned Earth-observing missions, such as Metop-C and Sentinel-5 precursor with their respective payloads GOME-2 and TROPOMI (Veefkind et al., 2012), will enable the extension of the existing cloud records until and beyond 2022, supporting attribution studies of cloud property changes to natural or human causes and assessments of the cloud feedback sign within the climate system. 


\section{Appendix A: Algorithm sensitivity to calibration drift}

In this appendix we assess the sensitivity of the SACURA algorithm to three distinct calibration errors. The question to be answered is whether the shifts in the time series of absolute values of CTH (see Fig. 1) can be caused by calibration differences among the three sensors used in this work.

To this purpose, an input radiance in the $\mathrm{O}_{2}$ A-band (in range $758-772 \mathrm{~nm}$ ) is simulated, neglecting polarization, with the radiative transfer model SCIATRAN (Rozanov et al., 2014). This corresponds to a single-layer cloud, placed at $5 \mathrm{~km}$ (top) and $4 \mathrm{~km}$ (bottom altitude) and optically thick 20. COT is set to 20 because its global distribution peaks about this value (Lelli et al., 2012). The solar zenith angle is set equal to $60^{\circ}$ with a dark underlying surface. From top to bottom of Fig. 15, the relative error (\%) in COT, the absolute error $(\mathrm{km})$ in CTH and CBH are plotted, respectively. For the black curves, the radiance is perturbed only at $\lambda=758 \mathrm{~nm}$. For the red curves, a constant offset has been added in range 758-772 nm, meaning a shift of the oxygen A-band. For the blue curves, a wavelength-dependent offset has been added to the whole band. The spectral behaviour of the calibration error has been taken from Noël (2005) and is considered linear from $\lambda=758 \mathrm{~nm}( \pm 0.86 \%)$ throughout $\lambda=772 \mathrm{~nm}$ $( \pm 0.80 \%)$. Clearly, this last error parameterization is also the most realistic as compared to the single-channel perturbation in the continuum outside the band.
From the analysis of Fig. 15, the following conclusions, relevant to the scope of this paper, can be drawn: first, spectral-dependent calibration errors have almost no impact on the retrieved CTH. The CTH bias (mid plot, blue curve) is stable about a value of $\approx 250 \mathrm{~m}$, which is the error introduced by the analytical forward model (Lelli et al., 2012, Fig. 1, p. 1556). Second, in case of calibration errors, cloud bottom height is the affected parameter. The bottom plot clearly shows that $\mathrm{CBH}$ becomes noisier. It can also be seen that errors in retrieved cloud optical thickness (top plot) do not influence the retrieved CTH and are independent of the applied error, because COT is retrieved at the single channel $\lambda=758 \mathrm{~nm}$, while CTH and CBH are retrieved across the whole A-band, after normalization to the average value of reflectance outside the band. Therefore, we conclude that the primary role in the shifts among time series of absolute CTH values (Fig. 1) is played by the different spatial resolution among the instruments and not by radiometric calibration. 
Acknowledgements. The authors are grateful to D. Loyola and W. von Hoyningen-Huene for discussions related to cloud and aerosol remote sensing. We also acknowledge S. Noël for providing the water vapour data set, $\mathrm{H}$. Bovensmann for his expertise in instrumental radiometry and $\mathrm{R}$. Hommel for suggestions on a draft version of the paper. The two anonymous reviewers and B. van Diedenhoven are credited for improving the paper as well. Special thanks go to W. Lotz for sharing his serious programming knowledge, which enabled accurate number crunching. SCIAMACHY and GOME-2 radiances have been made available by the European Space Agency (ESA) and the European Organization for the Exploitation of Meteorological Satellites (EUMETSAT), respectively. GOME radiances and $\mathrm{CF}$ data (for GOME and GOME-2) have been made available by the German Aerospace Centre (DLR) and generated under the auspices of the O3MSAF project funded by EUMETSAT and national contributions. Generic Mapping Tools (GMT, Wessel and Smith, 1998) and Climate Data Operators (CDO, Schulzweida et al., 2012) were used for this work. L. Lelli was supported by the DLR Sentinel-5 precursor project (grant no. 50EE1247).

Edited by: T. Garrett

\section{References}

Ackerman, A. S., Toon, O. B., Stevens, D. E., Heymsfield, A. J., Ramanathan, V., and Welton, E. J.: Reduction of Tropical Cloudiness by Soot, Science, 288, 1042-1047, doi:10.1126/science.288.5468.1042, 2000.

Allen, R. J., Sherwood, S. C., Norris, J. R., and Zender, C. S.: Recent Northern Hemisphere tropical expansion primarily driven by black carbon and tropospheric ozone, Nature, 485, 350-354, doi:10.1038/nature11097, 2012.

Bjerknes, J.: Atmospheric teleconnections from the Equatorial Pacific, Mon. Weather Rev., 97, 163-172, doi:10.1175/15200493(1969)097<0163:ATFTEP>2.3.CO;2, 1969.

Bovensmann, H., Burrows, J. P., Buchwitz, M., Frerick, J., Noël, S., Rozanov, V. V., Chance, K. V., and Goede, A. P. H.: SCIAMACHY: Mission objectives and measurement modes, J. Atmos. Sci., 56, 127-150, doi:10.1175/15200469(1999)056<0127:SMOAMM>2.0.CO;2, 1999.

Burrows, J. P., Weber, M., Buchwitz, M., Rozanov, V. V., Ladsttätter Weissenmayer, A., Richter, A., DeBeek, R., Hoogen, R., Bramstedt, K., Eichmann, K. U., Eisinger, M., and Perner, D.: The Global Ozone Monitoring Experiment (GOME): Mission Concept and First Scientific Results, J. Atmos. Sci., 56, 151-175, doi:10.1175/1520-0469, 1999.

Callies, J., Corpaccioli, E., Eisinger, M., Hahne, A., and Lefebvre, A.: GOME-2- Metop's second-generation sensor for operational ozone monitoring, ESA Bulletin, 102, 28-36, 2000.

Clement, A. C., Burgman, R., and Norris, J. R.: Observational and Model Evidence for Positive Low-Level Cloud Feedback, Science, 325, 460-464, doi:10.1126/science.1171255, 2009.

Davies, R. and Molloy, M.: Global cloud height fluctuations measured by MISR on Terra from 2000 to 2010, Geophys. Res. Lett., 39, L03701, doi:10.1029/2011GL050506, 2012.

Dessler, A. E.: Cloud variations and the Earth's energy budget, Geophys. Res. Lett., 38, L19701, doi:10.1029/2011GL049236, 2011.
Devasthale, A., Kruger, O., and Graß1, H.: Change in Cloud-Top Temperatures Over Europe, IEEE Geosci. Remote S., 2, 333336, 2005.

du Piesanie, A., Piters, A. J. M., Aben, I., Schrijver, H., Wang, P., and Noël, S.: Validation of two independent retrievals of SCIAMACHY water vapour columns using radiosonde data, Atmos. Meas. Tech., 6, 2925-2940, doi:10.5194/amt-6-2925-2013, 2013.

Eastman, R. and Warren, S. G.: A 39-Yr Survey of Cloud Changes from Land Stations Worldwide 1971-2009: Long-Term Trends, Relation to Aerosols, and Expansion of the Tropical Belt, J. Climate, 26, 1286-1303, doi:10.1175/JCLI-D-12-00280.1, 2013.

Efron, B. and Tibshirani, R. J.: An Introduction to the Bootstrap, Chapman \& Hall, New York, 1993.

Erlykin, A. D. and Wolfendale, A. W.: Global Cloud Cover and the Earth's Mean Surface Temperature, Surv. Geophys., 31, 399408, doi:10.1007/s10712-010-9098-7, 2010.

EUMETSAT: GOME-2 PMD Band Definitions 3.0 and PMD Calibration, Tech. Rep. EUM/OPS-EPS/DOC/07/0601, EUMETSAT, Darmstadt, Germany, 2010.

Evan, A. T. and Norris, J. R.: On global changes in effective cloud height, Geophys. Res. Lett., 39, L19710, doi:10.1029/2012GL053171, 2012.

Feingold, G.: On smoke suppression of clouds in Amazonia, Geophys. Res. Lett., 32, L02804, doi:10.1029/2004GL021369, 2005.

Koelemeijer, R. B. A., Stammes, P., Hovenier, J. W., and de Haan, J. F.: A fast method for retrieval of cloud parameters using oxygen A band measurements from the Global Ozone Monitoring Experiment, J. Geophys. Res., 106, 3475-3490, doi:10.1029/2000JD900657, 2001.

Koelemeijer, R. B. A., de Haan, J. F., and Stammes, P.: A database of spectral surface reflectivity in the range 335-772 $\mathrm{nm}$ derived from 5.5 years of 0.5 observations, J. Geophys. Res., 108, 4070, doi:10.1029/2002JD002429, 2003.

Kokhanovsky, A. A. and Rozanov, V. V.: The physical parameterization of the top-of-atmosphere reflection function for a cloudy atmosphere-underlying surface system: the oxygen A-band case study, J. Quant. Spectrosc. Ra., 85, 35-55, doi:10.1016/S00224073(03)00193-6, 2004.

Kokhanovsky, A. A., Mayer, B., Rozanov, V. V., Wapler, K., Burrows, J. P., and Schumann, U.: The influence of broken cloudiness on cloud top height retrievals using nadir observations of backscattered solar radiation in the oxygen A-band, J. Quant. Spectrosc. Ra., 103, 460-477, doi:10.1016/j.jqsrt.2006.06.003, 2007.

Laken, B., Palle, E., and Miyahara, H.: A Decade of the Moderate Resolution Imaging Spectroradiometer: Is a Solar-Cloud Link Detectable?, J. Climate, 25, 4430-4440, doi:10.1175/JCLID-11-00306.1, 2012.

Lelli, L., Kokhanovsky, A. A., Rozanov, V. V., Vountas, M., Sayer, A. M., and Burrows, J. P.: Seven years of global retrieval of cloud properties using space-borne data of GOME, Atmos. Meas. Tech., 5, 1551-1570, doi:10.5194/amt-5-1551-2012, 2012.

Loeb, N. G., Kato, S., Su, W., Wong, T., Rose, F. G., Doelling, D. R., Norris, J. R., and Huang, X.: Advances in Understanding Top-ofAtmosphere Radiation Variability from Satellite Observations, Surv. Geophys., 33, 359-385, doi:10.1007/s10712-012-9175-1, 2012. 
Loyola, D. G. and Ruppert, T.: A new PMD cloud-recognition algorithm for GOME, ESA Earth Observation Quarterly, 58, 45-47, 1998.

Loyola, D. G., Thomas, W., Spurr, R., and Mayer, B.: Global patterns in daytime cloud properties derived from GOME backscatter UV-VIS measurements, Int. J. Remote Sens., 31, 4295-4318, doi:10.1080/01431160903246741, 2010.

Marchand, R.: Trends in ISCCP, MISR, and MODIS cloud-topheight and optical-depth histograms, J. Geophys. Res.-Atmos., 118, 1941-1949, doi:10.1002/jgrd.50207, 2013.

Marshak, A., Davis, A., Wiscombe, W., and Titov, G.: The verisimilitude of the independent pixel approximation used in cloud remote sensing, Remote. Sens. Environ., 52, 72-78, doi:10.1016/0034-4257(95)00016-T, 1995.

Mieruch, S., Noël, S., Bovensmann, H., and Burrows, J. P.: Analysis of global water vapour trends from satellite measurements in the visible spectral range, Atmos. Chem. Phys., 8, 491-504, doi:10.5194/acp-8-491-2008, 2008.

Mudelsee, M.: Climate Time Series Analysis: Classical Statistical and Bootstrap Methods, Atmospheric and Oceanographic Sciences Library, Vol. 42, Springer, Dordrecht, Heidelberg, London, New York, doi:10.1007/978-90-481-9482-7, 2010.

Nakajima, T. and Schulz, M.: What Do We Know about Largescale Changes of Aerosols, Clouds, and the Radiation Budget?, in: Clouds in the Perturbed Climate System, edited by Heintzenberg, J. and Charlson, R. J., Strüngmann Forum Reports, 401432, MIT Press, Cambridge, Massachusetts, 2009.

Noël, S.: Determination of Correction Factors for SCIAMACHY Radiances and Irradiances, Tech. Rep. IFE-SCIA-SN-20050203 (Issue 5.2), Institute of Environmental Physics and Remote Sensing, University of Bremen, Germany, http://www.iup. uni-bremen.de/sciamachy/SCIA_CAL/irrad_corr.pdf (last access: March 2014), 2005.

Noël, S., Buchwitz, M., and Burrows, J. P.: First retrieval of global water vapour column amounts from SCIAMACHY measurements, Atmos. Chem. Phys., 4, 111-125, doi:10.5194/acp-4-1112004, 2004.

Noël, S., Buchwitz, M., Bovensmann, H., and Burrows, J. P.: Validation of SCIAMACHY AMC-DOAS water vapour columns, Atmos. Chem. Phys., 5, 1835-1841, doi:10.5194/acp-5-18352005, 2005.

Norris, J. R.: Has northern Indian Ocean cloud cover changed due to increasing anthropogenic aerosol?, Geophys. Res. Lett., 28, 3271-3274, doi:10.1029/2001GL013547, 2001.

Norris, J. R.: Trends in upper-level cloud cover and surface divergence over the tropical Indo-Pacific Ocean between 1952 and 1997, J. Geophys. Res., 110, D21110, doi:10.1029/2005JD006183, 2005.

Rozanov, V. V. and Kokhanovsky, A. A.: Semianalytical cloud retrieval algorithm as applied to the cloud top altitude and the cloud geometrical thickness determination from top-of-atmosphere reflectance measurements in the oxygen A band, J. Geophys. Res., 109, 4070, doi:10.1029/2003JD004104, 2004.

Rozanov, V. V., Rozanov, A. V., Kokhanovsky, A. A., and Burrows, J. P.: Radiative transfer through terrestrial atmosphere and ocean: Software package SCIATRAN, J. Quant. Spectrosc. Ra., 133, 13-71, doi:10.1016/j.jqsrt.2013.07.004, 2014.

Schulzweida, U., Müller, R., Kornblüh, L., Ansorge, C., and Quast, R.: CDO - Climate Data Operators - v1.5.9, Center for Ma- rine and Atmospheric Sciences (ZMAW), Max-Planck Institute for Meteorology, University of Hamburg, https://code.zmaw.de/ projects/cdo (last access: July 2012), 2012.

Singh, M. S. and O'Gorman, P. A.: Upward Shift of the Atmospheric General Circulation under Global Warming: Theory and Simulations, J. Climate, 25, 8259-8276, doi:10.1175/JCLI-D11-00699.1, 2012.

Solomon, A. and Newman, M.: Reconciling disparate twentiethcentury Indo-Pacific ocean temperature trends in the instrumental record, Nature Climate Change, 2, 691-699, doi:10.1038/NCLIMATE1591, 2012.

Stubenrauch, C. J., Rossow, W. B., Kinne, S., Ackerman, S., Cesana, G., Chepfer, H. Getzewich, B., Di Girolamo, L., Guignard, A., Heidinger, A., Maddux, B., Menzel, P., Minnis, P., Pearl, C., Platnick, S., Riedi, J., Sun-Mack, S., Walther, A., Winker, D., Zeng, S., and Zhao, G.: Assessment of Global Cloud Datasets from Satellites: Project and Database Initiated by the GEWEX Radiation Panel, B. Am. Meteorol. Soc., 94, 10311049, doi:10.1175/BAMS-D-12-00117.1, 2013.

Trenberth, K. E.: The definition of El Niño, B. Am. Meteorol. Soc., 78, 2771-2777, doi:10.1175/15200477(1997)078<2771:TDOENO>2.0.CO;2, 1997.

Turner, A. and Annamalai, H.: Climate change and the South Asian summer monsoon, Nature Climate Change, 2, 587-595, doi:10.1038/nclimate1495, 2012.

U. S. National Centers for Environmental Prediction (NCEP): Oceanic Niño Index (ONI), National Oceanic and Atmospheric Administration (NOAA), http://www.cpc.ncep.noaa.gov/ products/precip/CWlink/MJO/enso.shtml, (last access: January 2013), 1993.

van Diedenhoven, B., Hasekamp, O. P., and Aben, I.: Surface pressure retrieval from SCIAMACHY measurements in the $\mathrm{O}_{2} \mathrm{~A}$ Band: validation of the measurements and sensitivity on aerosols, Atmos. Chem. Phys., 5, 2109-2120, doi:10.5194/acp-5-21092005, 2005.

Veefkind, J. P., Aben, I., McMullan, K., Förster, H., de Vries, J., Otter, G., Claas, J., Eskes, H. J., de Haan, J. F., Kleipool, Q., Van Weele, M., Hasekamp, O., Hoogeveen, R., Landgraf, J., Snel, R., Tol, P., Ingmann, P., Voors, R., Kruizinga, B., Vink, R., Visser, H., and Levelt, P. F.: TROPOMI on the ESA Sentinel-5 Precursor: A GMES mission for global observations of the atmospheric composition for climate, air quality and ozone layer applications, Remote Sens. Environ., 120, 70-83, doi:10.1016/j.rse.2011.09.027, 2012.

Wagner, T., Beirle, S., Deutschmann, T., Grzegorski, M., and Platt, U.: Dependence of cloud properties derived from spectrally resolved visible satellite observations on surface temperature, Atmos. Chem. Phys., 8, 2299-2312, doi:10.5194/acp-8-2299-2008, 2008.

Wessel, P. and Smith, W. H. F.: New, improved version of Generic Mapping Tools (GMT) released, Eos Trans. AGU, 79, 579-579, doi:10.1029/98EO00426, 1998

Wilks, D. S.: Statistical Methods in the Atmospheric Sciences, Vol. 100, Third Edn., (International Geophysics), Academic Press, San Diego, USA, 2011. 